\title{
Food Security in an Uncertain World
}

Sabine Fuss Ecosystems Services \& Management Program

$40^{\text {th }}$ Anniversary IIASA Conference October 24th 2012 Hofburg, Vienna 


\section{Food security}

Current FAO definition (1998):

"Food security exists when all people, at all time, have physical and economic access to sufficient, safe and nutritious food that meets their dietary needs and food preferences for an active and healthy life. 


\section{0 million remain hungry in 2010-2012}

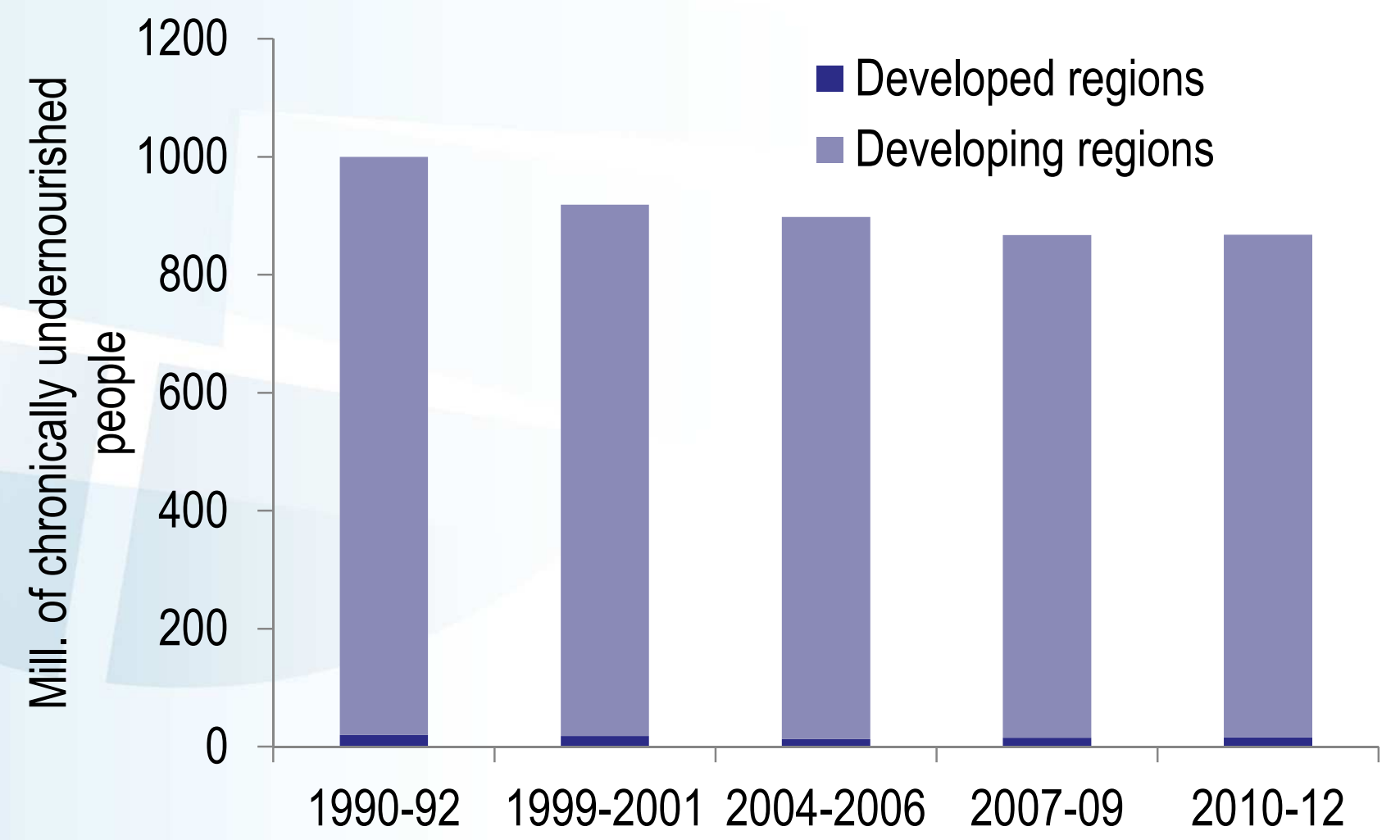

Source: FAO, SOFI 2012 


\section{Short-run dynamics vs. long-run trends}

\section{FAO Food Price Index in real terms, 1961-2010}

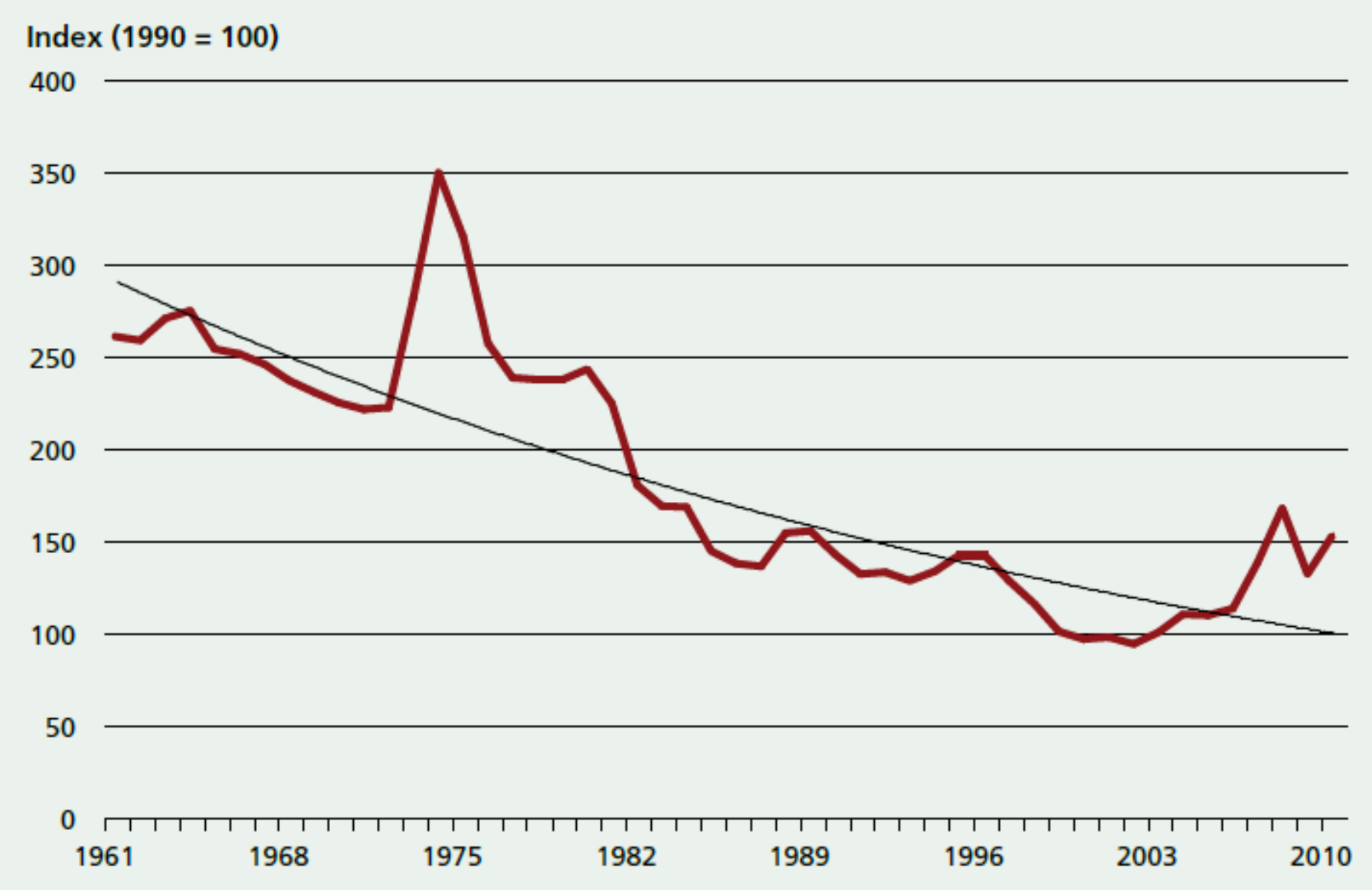

Source: FAO, SOFA2011 


\section{Food security within planetary boundaries}

- Food prices and price volatility

- Population \& food demand growth, rapid diet transitions

- Competition for land (e.g. bioenergy)

- Declining investment in food system research

- Pressure on water and other resources

- Migration: international and from rural to urban areas

- Political and economic instability

- Climate change \& uncertainty

$\Rightarrow$ We need an integrated systems approach to tackle these challenges comprehensively and sustainably. 


\section{Food security within planetary boundaries}

- Food prices and price volatility

- Population \& food demand growth, rapid diet transitions

- Competition for land (e.g. bioenergy)

- Declining investment in food system research

- Pressure on water and other resources

- Migration: international and from rural to urban areas

- Political and economic instability

- Climate change \& uncertainty

$\Rightarrow$ We need an integrated systems approach to tackle these challenges comprehensively and sustainably. 


\section{A flavor of climate change uncertainty}
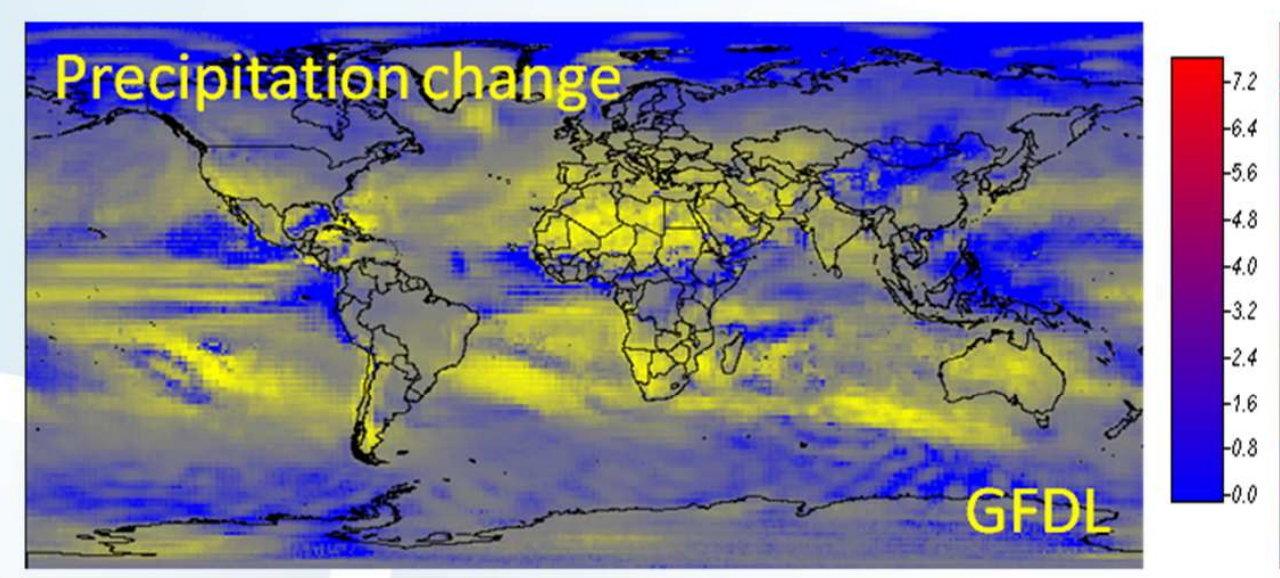

Temperature change
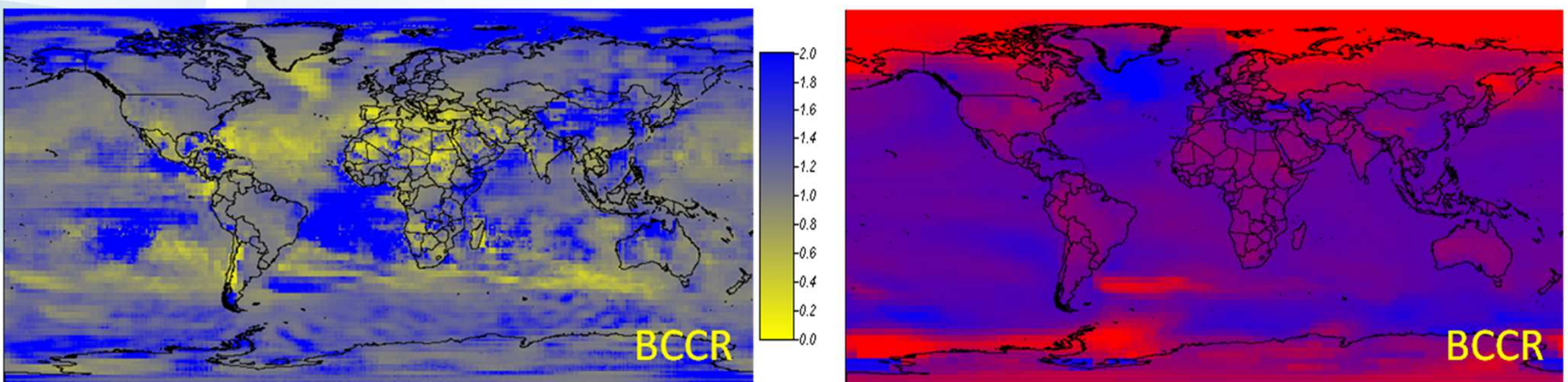

s. 


\section{Climate Change Impacts on Corn Yield}

\section{Corn (World agg.)}

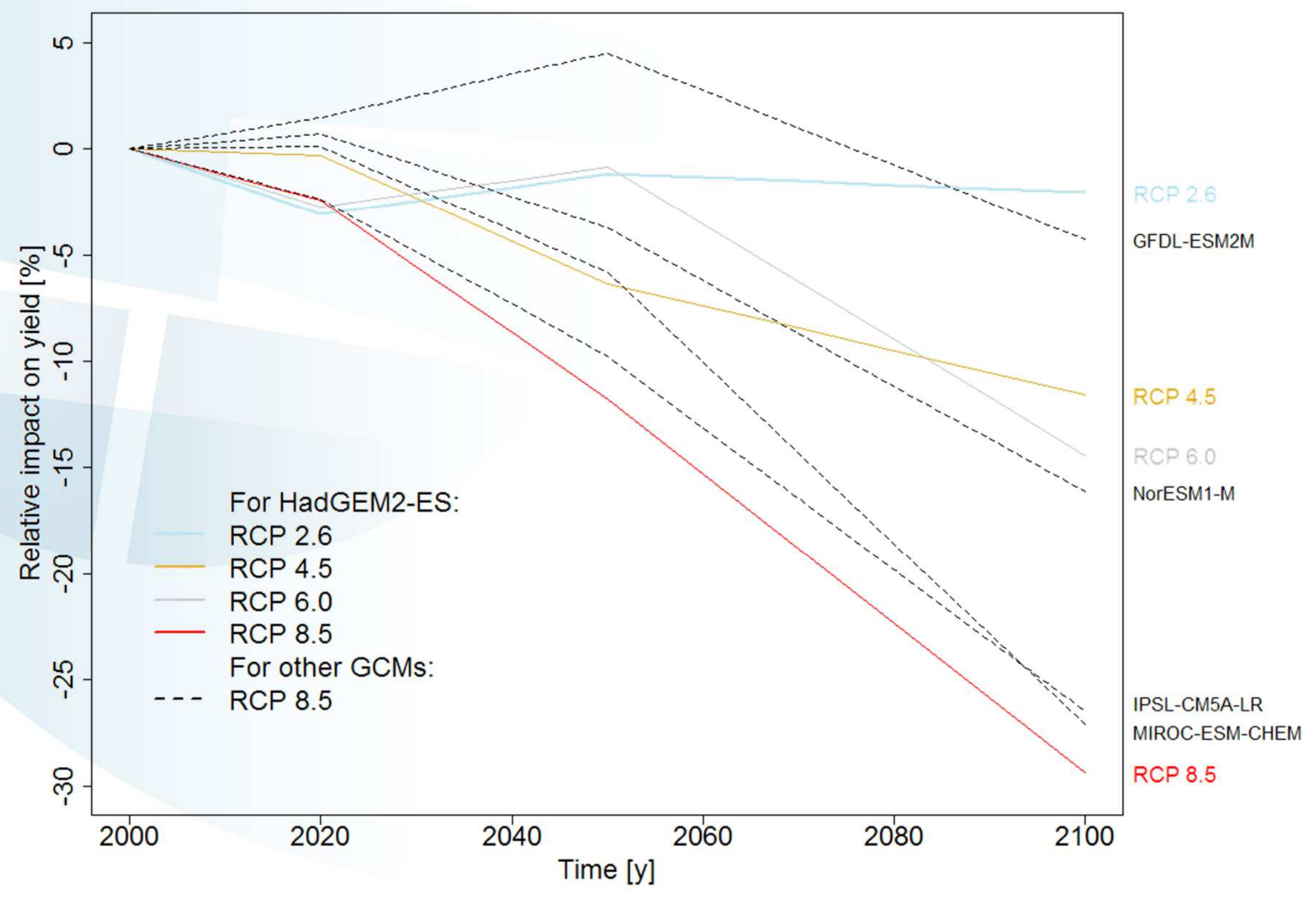




\section{Robustness}

- State-of-the-art: strategies optimal for each scenario.

- But this only outlines the scope of potential outcomes.

- Not ensured that strategies are robust across different futures.

$\Rightarrow$ Find the strategy ensures food security, no matter which scenario materializes!

- Use ESM's Global Biosphere Management Model GLOBIOM to determine robust strategies across climate scenarios. 


\section{Welfare in 2050}

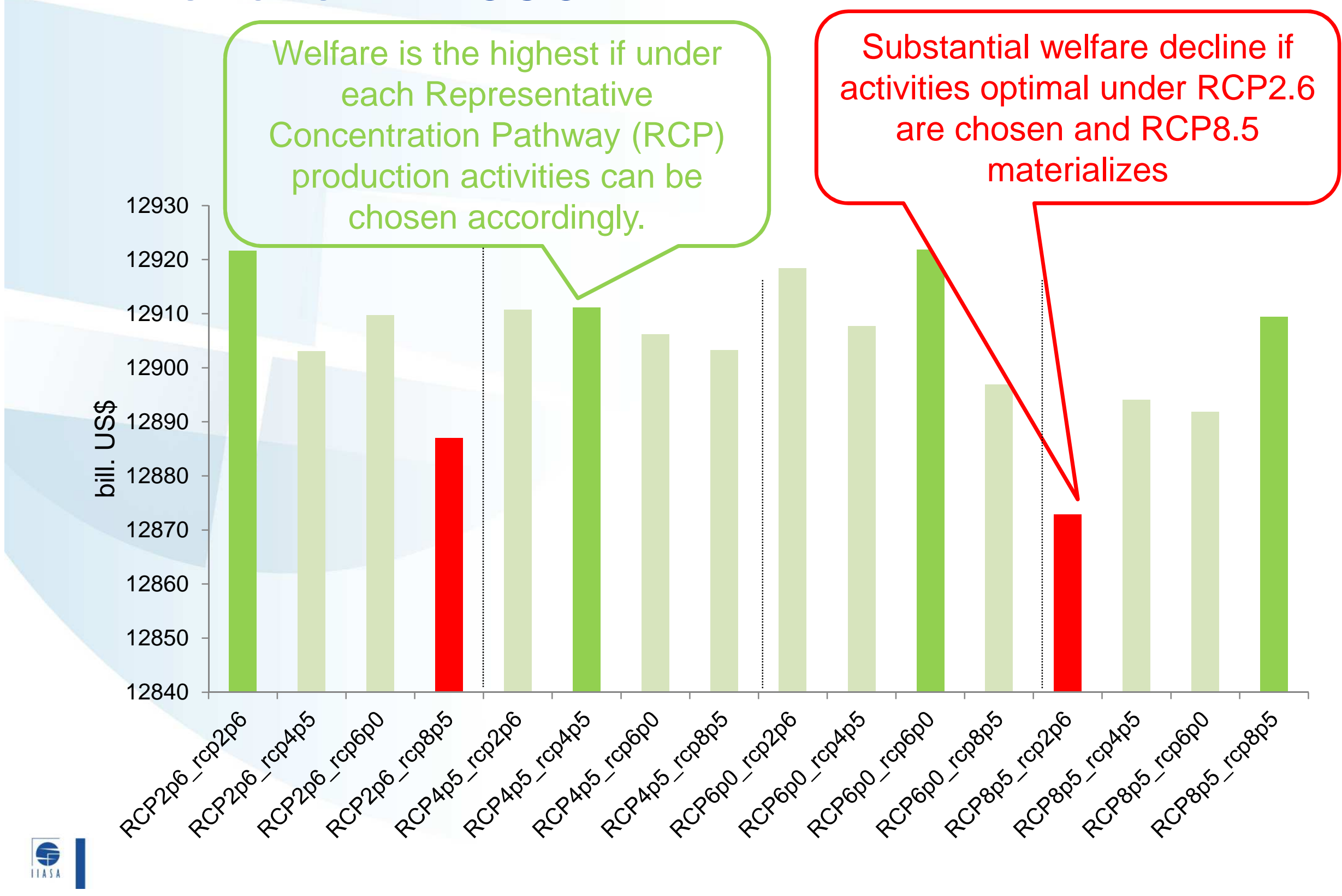




\section{Food prices in 2050}

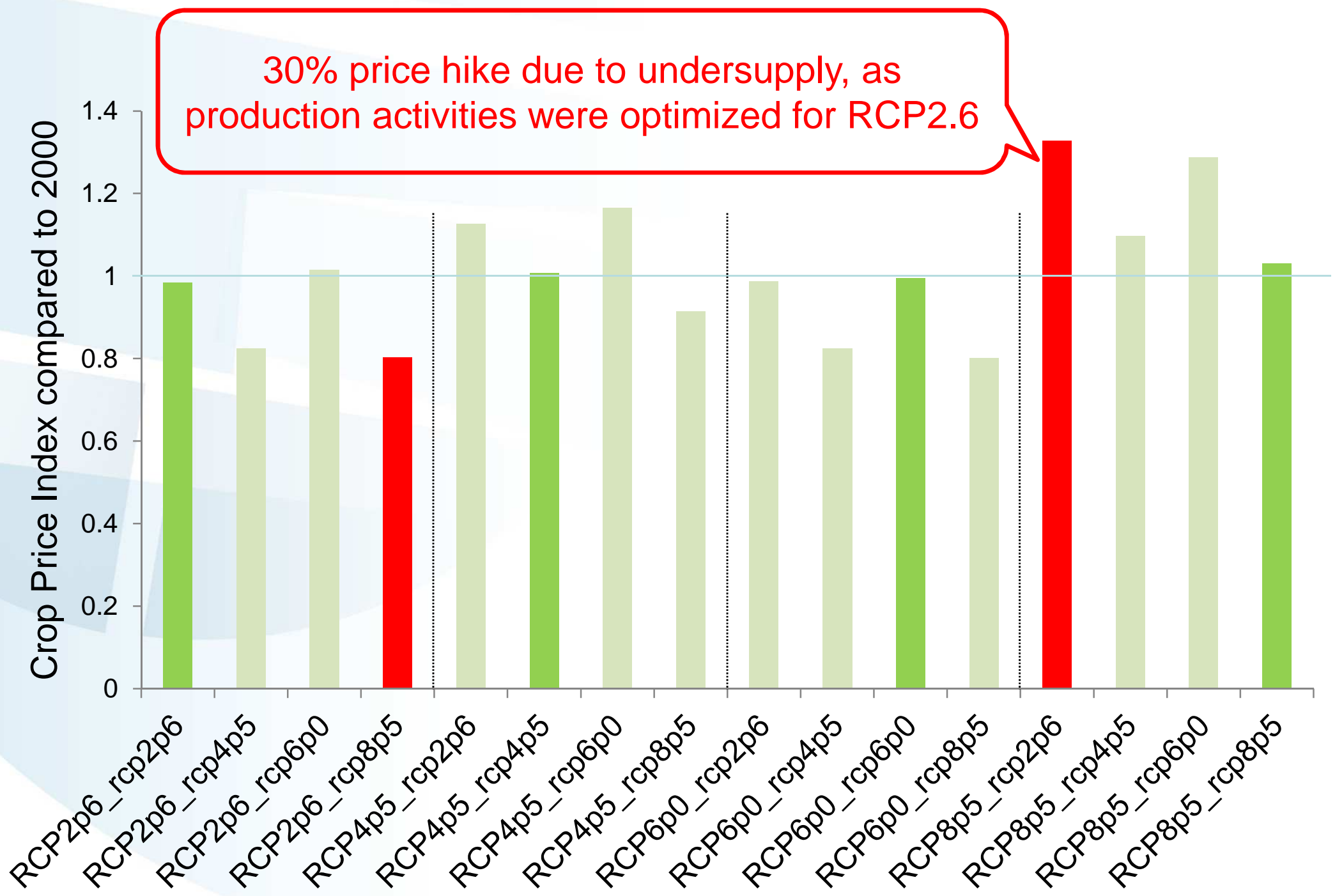




\section{Lessons learnt}

- No single adaptation policy superior across all climate scenarios.

- Locking into a particular agricultural system superior under one climate scenario can imply substantial losses if a different climate scenario materializes.

- A robust strategy in an uncertain world:

- Flexibility-enhancing measures: access to irrigation, seeds \& fertilizers, market access.

- Resolving uncertainty and planning robustly can lead to substantial savings.

- Reducing the extent of over- and underproduction and the accompanying environmental implications (land use change). 


\section{Contact:}

Sabine Fuss fuss@iiasa.ac.at

Ecosystems Services and Management Program

International Institute for Applied Systems Analysis (IIASA)

Schlossplatz 1

A-2361 Laxenburg, Austria

More information on GLOBIOM model: www.globiom.org and www.iiasa.ac.at

This work received the support from the following FP7 projects :

- $\quad$ ANIMAL CHANGE (grant no. 266018)

- FOODSECURE (grant no. 290693)

- $\quad$ Global-IQ (grant no. 266992)

The views expressed in this document are the sole personal responsibility of the authors and do not reflect those the Commission which has not viewed, let alone approved the content of the document. The document does not reflect the views of the institutions of affiliation of the authors either.

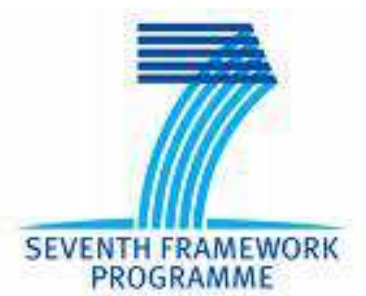

